\title{
Peer Review Comments Provided by High- and Low-Proficiency L2 Learners: A Comparative Study
}

\author{
Hui-Chuan Liao ${ }^{1}$ \& Ya-Fen Lo ${ }^{1}$ \\ ${ }^{1}$ Department of Applied Foreign Languages, National Kaohsiung University of Applied Sciences, Taiwan \\ Correspondence: Hui-Chuan Liao, Department of Applied Foreign Languages, National Kaohsiung University of \\ Applied Sciences, 415 Chien-Kung Road, Kaohsiung 80778, Taiwan. Tel: 886-7-381-4526 ext. 3278. E-mail: \\ hliao@kuas.edu.tw
}

Received: June 17, 2012

Accepted: July 30, 2012 Online Published: August 30, 2012

doi:10.5539/ijel.v2n5p45

URL: http://dx.doi.org/10.5539/ijel.v2n5p45

\begin{abstract}
This study explored the variations in peer review comments provided by L2 writers of high and low proficiencies. Two sampling procedures were used. First, convenience sampling was used to locate a college essay composition course as the setting of the study. Second, purposeful sampling was used to identify high- and low-performing writers as the subjects, from whom the peer review comments were collected and analyzed. An instruction-learning cycle on argumentative essay writing was conducted for 4 weeks. Each student was subsequently provided with the same sample argumentative essay and a peer review form to conduct the review. The rubrics on the review form included introduction, support for position, sequence, refutation, conclusion, voice, and grammar and spelling. Content analysis was conducted to compare the manner in which the comments varied among students of different writing proficiency levels. The results indicate that, although identifying problems was the dominant comment type of both high- and low-performing writers, high-performing writers tended to provide more details when explaining the identified problems and offering suggestions for revisions. The findings are discussed regarding the implications to peer review training.
\end{abstract}

Keywords: language proficiency, peer review, peer review training, writing instruction

\section{Introduction}

Although writing is frequently considered a personal undertaking, real-life professional writing often requires teamwork in order to integrate expertise and enhance the level of persuasion by incorporating various viewpoints (Bargiela-Chiappini \& Nickerson, 1999; Hyland, 2003). An approach to providing students with opportunities to practice negotiation of meanings and enhance collaborative writing skills needed in the workplace (Hyland, 2003) is to use peer review or peer response groups in a writing class. Previous studies indicate students benefit from peer interaction and support in the composing process, not just from comments regarding a final product (Hyland, 2000). Perceiving the potential advantage of incorporating the element of peer review into writing instruction programs, the researchers explored the manner in which peer review comments differed among L2 writers of high and low proficiencies, and subsequently used the information to discuss possible implications to refine the design of peer review training programs in future studies.

The use of peer review in an L2 writing program is consistent with the learning theories of Vygotsky $(1962,1978)$ and Dewey (1963). Vygotsky (1978) argued that collaboration among peers promotes learning because the process enables learners to operate within each other's “zone of proximal development” (p. 86). Working with peers is academically beneficial because, when learners are closer to each other in their levels of proximal development, they can describe things to each other in a simpler manner that can be comprehended more easily than an explanation by a person with a different mental stage. Similarly, Dewey (1963) stressed the importance of "active cooperation" in the process of constructing knowledge (p. 67).

The beneficial effects of peer review are threefold. First, comments by peer reviewers increase the audience awareness of writers and help them enhance the quality of writing when the "writer-based prose" is revised to a more "reader-based" piece of work (Flower \& Hayes, 1981). Second, when critically reading each other's drafts, the reviewing process enables reviewers to reflect more upon the writing and revision process, which enhances 
their judgment of what makes a writing piece good (Min, 2003). Third, the reviewing process enables reviewers to enhance the awareness of their own composition, which helps them become superior writers (Stoddard \& MacAuthur, 1993). However, although prior research has indicated the merits of peer interaction in the writing process, in order to maximize the effects of peer support, it is crucial to understand the manner in which learners of different characteristics write and revise before effective writing instructions and writing programs can be designed.

Prior studies have shown that more proficient writers focus on the global aspects of their writing, such as organization and audience (Cohen \& Cavalcanti, 1990; Zamel, 1982, 1983). Conversely, less proficient writers usually have a narrower approach and focus on vocabulary and the surface grammar structure (Pianko, 1979; Porte, 1996, 1997). Experienced writers can foresee readers' comprehension needs and tailor their writing accordingly with respect to content and linguistic elements; however, this is difficult for novice writers (Flower \& Hayes, 1980). In this regard, peer review can assist a novice writer in considering the writing piece from the perspective and state of mind of the reader (Hyland, 2003).

Prior research has also indicated L2 proficiency as an important factor in the quality of writing and problem-solving behavior (Plakans, 2008; Roca de Larios, Manchon, Murphy, \& Marin, 2008; Roca de Larios, Murphy, \& Marin, 2002; Zamel, 1983). Particularly, reading ability has been found to be a key factor that affects reading-to-write performance. For example, the amount of notes and the sophistication of the content of the notes are influenced by reading levels of the learner (Kennedy, 1985). According to Connor and Krammer (1995) and Delaney (2008), less proficient L2 learners can have difficulty in writing or reading-to-write tasks because they tend to lack the necessary vocabulary and grammar at the sentence level or reading comprehension and writing competence at the discourse level.

Even though previous research studies have found that learners vary in their writing strategies and performances, little research has pinpointed at the peer review behaviors among L2 learners of different proficiencies. Therefore, the present study bridges the gap in the literature by exploring possible variations between the peer review comments of high- and low-proficiency L2 learners.

\section{Method}

In order to examine peer review comments provided by L2 writers of different proficiency levels, the study used both convenience and purposeful sampling, including extreme-case sampling, to identify the participants, from whom the data of peer comments were collected at the end of a 4-week peer review instructional-learning cycle. The sampling procedure, peer review training, data collection, and data analysis are shown in Figure 1 and discussed in the subsequent sections.

\subsection{Subjects}

The researchers used two sampling procedures to recruit participants. First, convenience sampling was used. A college English essay writing course in an urban technical university in Taiwan was selected as the setting of the study. The course was compulsory for English majors. The essay writing course focused on argumentation and had an enrollment of 29 students. Subsequently, two purposeful sampling methods were used. First, students at the top and bottom quartiles were identified based on the average scores of the midterm and final essay writing in the previous semester $(M=83.7, S D=7.4)$. The seven higher-performing writers at the top quartile $(M=88.7)$ are referred to as $\mathrm{H} 1$ to $\mathrm{H} 7$ in this paper, whereas the seven lower-performing writers at the bottom quartile $(\mathrm{M}=$ 75.2) are referred to as L1 to L7. Regarding the general English proficiency of the participants, the top quartile had an average of 573 points on the Test of English for International Communication (TOEIC) listening and reading, and the bottom quartile 496 points. Based on the Common European Framework of Reference for Languages (CEFR), the learners in the top quartile were at the B1 level (i.e., threshold or pre-intermediate level), and those in the bottom quartile were at the A2 level (i.e., waystage or elementary level).

After the learners at the top and bottom quartiles were identified, extreme-case sampling (McMillan \& Schumacher, 1997) was used to select cases that represented the most clear cut instance of language performance. With an analysis on the essay writing scores of the previous semester, the researchers identified six learners whose writing scores were more than one standard deviation away from the mean, that is, higher than 91.1 (H1, H2, and H3) or lower than 76.3 (L1, L2, and L3). The top three writers had an average of 733 points on the TOEIC and the bottom three had 467 points, which were equivalent to B1 and A2 levels, respectively. Table 1 shows an overview of the English proficiencies of the participants. 


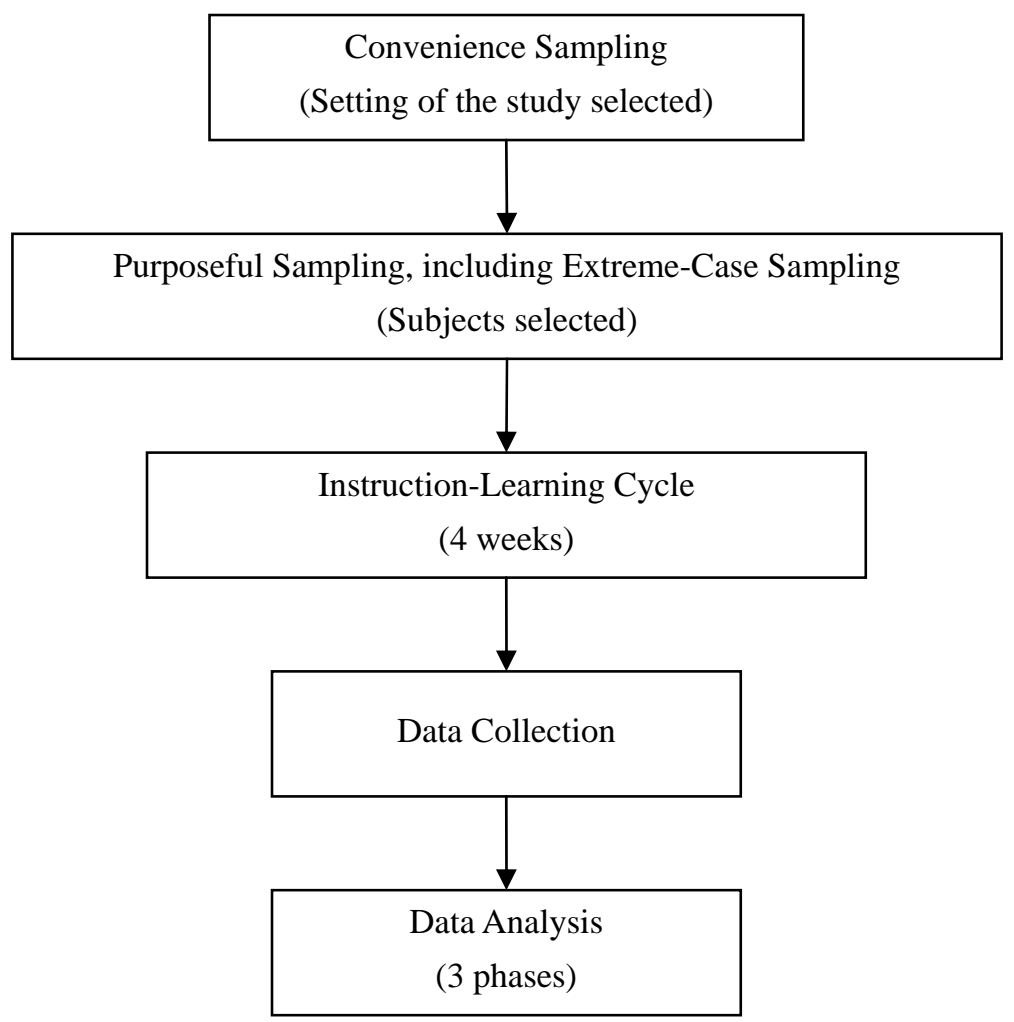

Figure 1. Research procedure of the study

Table 1. English proficiencies of the subgroups

\begin{tabular}{lccc}
\hline \multicolumn{1}{c}{ Subgroups } & Coding & Writing Score Average & TOEIC Score Average \\
\hline Top 3 & H1 to H3 & 93.8 & 733 \\
Top Quartile & H1 to H7 & 88.7 & 573 \\
Bottom Quartile & L1 to L7 & 75.2 & 496 \\
Bottom 3 & L1 to L3 & 68.8 & 467 \\
Class & N/A & 83.7 & 553 \\
\hline
\end{tabular}

\subsection{Instruction-learning Cycle}

Before data collection, the students learned skills of argumentative essay writing through lectures provided by the instructor as well as reading and analyses of two example argumentative essays. The lectures included the six-paragraph organization of argumentative essays, development of thesis, adding supporting information, counterargument and refutation, controlling tone with modals, and selection of topics appropriate for argumentative essays. In-class learning activities were conducted at each step of the lectures. The activities included identifying key components of an argumentative essay (e.g., thesis, supporting sentences, counterargument, and refutation), providing supporting information, writing pro and con thesis statements, selecting modals, constructing a topic for argumentation, and planning an outline. The instruction-learning cycle was implemented over 4-weeks.

\subsection{Data Collection and Analysis}

In the fifth week, the participants were provided with a 453-word sample argumentative essay to conduct a peer review. The instructor explained the format of the evaluation and feedback form, as well as the rubrics for 
evaluation in 30 minutes. Next, content analysis was conducted to analyze the types of comments provided by the participants and to determine the manner in which the comments of the four subgroups differed. Prior research identified four comment types (Min, 2005, 2009) that facilitate the revisions of learners (Mendonca \& Johnson, 1994; Stanley, 1992; Tang \& Tithecott, 1999; Villamil \& De Guerrero, 1996). The four comment types were used as guidelines in the initial phase of analysis. They included clarification, identification of problems, explanation, and suggestion. Based on the guidelines, two independent raters used parentheses to mark each comment and coded each of them as CL (clarification), ID (identification of problems), EX (explanation), or SG (suggestion). Two experienced writing teachers served as the raters. One was a Taiwanese teacher who worked in Canada for 13 years before returning to Taiwan to teach. She received her Ph.D. in Teaching English to Speakers of Other Languages and had taught English for 13 years and writing in particular for nine years. The other rater was the primary researcher of this study.

The raters realized the necessity to add an extra category to describe comments that intended to acknowledge the efforts of the writer or encourage the writer by indicating the strength of the piece. Therefore, a fifth comment type, encouragement, emerged as a result of the analysis. Next, the analysis entered the second phase with the raters re-examining the texts using all five comment types. In the third phase of analysis, the raters counted the number of comments, number of comments under each comment type, and number of words per comment to evaluate the quality of peer review, and the inter-rater reliability was 100\%, $91 \%$ and $100 \%$, respectively.

\section{Results}

\subsection{Frequency of Comments in Different Comment Types}

As shown in Table 2, the top three and bottom three students provided an average of 14.7 and 11.0 comments, respectively. The students in the top and bottom quartiles provided an average of 12.3 and 9.3 comments, respectively. Among the five comment types, identification of problems was dominant among the four subgroups of writers. Neither of the comparison pairs, that is, top three versus bottom three or top quartile versus bottom quartile, showed big differences in the frequency of comments in individual comment types.

Differences between the high- and low-performing writers became more distinct when the data were further examined through the calculation of the percentage of comments in different comment types. Although the identification of problems remained the primary comment type provided by all subgroups $(49.3 \%, 70.5 \%, 51.4 \%$ and $58.0 \%$ for the top three, bottom three, top quartile, and bottom quartile, respectively), the bottom-three group provided a lower percentage of comments than the top-three group in explaining problems (9.9\% vs. $16.0 \%$ ), making suggestions $(2.4 \%$ vs. $7.6 \%)$, and encouraging the writer $(14.7 \%$ vs. $27.1 \%)$. Similarly, the bottom-quartile group provided a lower percentage of comments than the top-quartile group in explaining problems (6.6\% vs. $9.4 \%)$ and making suggestions (3.4\% vs. $8.5 \%)$.

\subsection{Word Counts in Different Comment Types}

Although the top three and bottom three writers provided a similar number of comments, the former provided more in-depth comments, regardless of whether the five comment types were considered separately or together. As indicated in Table 3, the top-three group on average had a total word count of 158.3 words in the comments, whereas the bottom-three group had only 116.3 words on average. Additionally, the top-three group provided more words than the bottom-three group in the comment types of explanation, suggestion, and encouragement, with 31.3 versus 19.3, 20.3 versus 5.0, and 52.0 versus 33.3 words, respectively.

The gap remained noticeable, although smaller, between the students in the top and bottom quartiles. The top quartile on average had a total word count of 133.9 words in the comments, while the bottom quartile had only 100.7 words on average. Furthermore, the top quartile provided more words than the bottom quartile in the comment types of explanation, suggestion, and encouragement, with 16.4 versus 9.4, 18.9 versus 3.4, and 47.7 versus 38.0 words, respectively.

In addition, whereas Table 3 shows the highest percentage or words in the comment type of identification for all four ability subgroups (34.9\%, 61.4\%, 38.9\% and 52.4\% for the top three, bottom three, top quartile, and bottom quartile, respectively), the two higher ability groups, that is, the top-three group and the top-quartile group, also had high percentage of words in encouraging the writer (30.0\% and $34.2 \%$, respectively).

\subsection{Words per Comment}

Regarding words per comment (see Table 4), the largest discrepancy was found in the category of suggestion. The top three writers on average provided 12.7 words per comment, while the bottom three writers on average only provided 5.0 words per comment. In a similar vein, the students in the top quartile on average provided 13.4 words per comment in the suggestion category, which was apparently higher than the average of 3.4 words per 
comment provided by those in the bottom quartile.

Table 2. Frequency of comments

\begin{tabular}{|c|c|c|c|c|c|c|}
\hline \multirow{2}{*}{ Students ${ }^{\mathrm{a}}$} & \multicolumn{5}{|c|}{ Comment Types $^{\text {b }}$} & \multirow{2}{*}{$\begin{array}{c}\text { Total } \\
\text { Comments }\end{array}$} \\
\hline & CL & ID & EX & SG & EN & \\
\hline H1 & 0 & 7 & 2 & 0 & 7 & 16 \\
\hline $\mathrm{H} 2$ & 0 & 10 & 3 & 1 & 2 & 16 \\
\hline H3 & 0 & 5 & 2 & 2 & 3 & 12 \\
\hline $\mathrm{H} 4$ & 0 & 6 & 0 & 0 & 3 & 9 \\
\hline H5 & 0 & 5 & 0 & 1 & 5 & 11 \\
\hline H6 & 0 & 6 & 1 & 2 & 2 & 11 \\
\hline H7 & 0 & 5 & 1 & 1 & 4 & 11 \\
\hline L7 & 0 & 4 & 0 & 0 & 4 & 8 \\
\hline L6 & 0 & 2 & 1 & 1 & 2 & 6 \\
\hline L5 & 0 & 5 & 0 & 0 & 4 & 9 \\
\hline L4 & 0 & 5 & 0 & 0 & 4 & 9 \\
\hline L3 & 1 & 8 & 2 & 0 & 2 & 13 \\
\hline L2 & 0 & 7 & 2 & 1 & 4 & 14 \\
\hline L1 & 0 & 6 & 0 & 0 & 0 & 6 \\
\hline
\end{tabular}

Proficiencies Categorized by Extreme-Case Sampling

\begin{tabular}{|c|c|c|c|c|c|c|}
\hline Top 3 Average & $\begin{array}{c}0 \\
(0 \%)\end{array}$ & $\begin{array}{c}7.3 \\
(49.3 \%)\end{array}$ & $\begin{array}{c}2.3 \\
(16.0 \%)\end{array}$ & $\begin{array}{c}1.0 \\
(7.6 \%)\end{array}$ & $\begin{array}{c}4.0 \\
(27.1 \%)\end{array}$ & $\begin{array}{c}14.6 \\
(100 \%)\end{array}$ \\
\hline Bottom 3 Average & $\begin{array}{c}0.3 \\
(2.6 \%)\end{array}$ & $\begin{array}{c}7.0 \\
(70.5 \%)\end{array}$ & $\begin{array}{c}1.3 \\
(9.9 \%)\end{array}$ & $\begin{array}{c}0.3 \\
(2.4 \%)\end{array}$ & $\begin{array}{c}2.0 \\
(14.7 \%)\end{array}$ & $\begin{array}{c}11.0 \\
(100 \%)\end{array}$ \\
\hline \multicolumn{7}{|c|}{ Proficiencies Categorized by Quartiles } \\
\hline Top Quartile Average & $\begin{array}{c}0 \\
(0 \%)\end{array}$ & $\begin{array}{c}6.3 \\
(51.4 \%)\end{array}$ & $\begin{array}{c}1.3 \\
(9.4 \%)\end{array}$ & $\begin{array}{c}1.0 \\
(8.5 \%)\end{array}$ & $\begin{array}{c}3.7 \\
(30.7 \%)\end{array}$ & $\begin{array}{c}12.3 \\
(100 \%)\end{array}$ \\
\hline Bottom Quartile Average & $\begin{array}{c}0.1 \\
(1.1 \%)\end{array}$ & $\begin{array}{c}5.3 \\
(58.0 \%)\end{array}$ & $\begin{array}{c}0.7 \\
(6.6 \%)\end{array}$ & $\begin{array}{c}0.3 \\
(3.4 \%)\end{array}$ & $\begin{array}{c}2.9 \\
(30.9 \%)\end{array}$ & $\begin{array}{c}9.3 \\
(100 \%)\end{array}$ \\
\hline
\end{tabular}


Table 3. Word counts

\begin{tabular}{|c|c|c|c|c|c|c|}
\hline \multirow{2}{*}{ Students ${ }^{\mathrm{a}}$} & \multicolumn{5}{|c|}{ Comment Types ${ }^{\text {b }}$} & \multirow{2}{*}{$\begin{array}{c}\text { Total } \\
\text { Comments }\end{array}$} \\
\hline & CL & ID & EX & SG & EN & \\
\hline H1 & 0 & 55 & 31 & 0 & 109 & 195 \\
\hline H2 & 0 & 73 & 42 & 15 & 19 & 149 \\
\hline H3 & 0 & 36 & 21 & 46 & 28 & 131 \\
\hline $\mathrm{H} 4$ & 0 & 44 & 0 & 0 & 24 & 68 \\
\hline H5 & 0 & 88 & 0 & 23 & 80 & 191 \\
\hline H6 & 0 & 18 & 8 & 30 & 28 & 84 \\
\hline $\mathrm{H} 7$ & 0 & 42 & 13 & 18 & 46 & 119 \\
\hline L1 & 0 & 28 & 0 & 0 & 0 & 28 \\
\hline L2 & 0 & 53 & 16 & 15 & 62 & 146 \\
\hline L3 & 11 & 84 & 42 & 0 & 38 & 175 \\
\hline L4 & 0 & 43 & 0 & 0 & 36 & 79 \\
\hline L5 & 0 & 66 & 0 & 0 & 52 & 118 \\
\hline L6 & 0 & 12 & 8 & 9 & 19 & 48 \\
\hline L7 & 0 & 52 & 0 & 0 & 59 & 111 \\
\hline \multicolumn{7}{|c|}{ Proficiencies Categorized by Extreme-Case Sampling } \\
\hline \multirow{2}{*}{ Top 3 Average } & 0 & 54.7 & 31.3 & 20.3 & 52.0 & 158.3 \\
\hline & $(0 \%)$ & (34.9\%) & $(20.0 \%)$ & (15.1\%) & (30.0\%) & $(100 \%)$ \\
\hline \multirow{2}{*}{ Bottom 3 Average } & 3.7 & 55.0 & 19.3 & 5.0 & 33.3 & 116.3 \\
\hline & $(2.1 \%)$ & $(61.4 \%)$ & $(11.7 \%)$ & $(3.4 \%)$ & $(21.4 \%)$ & $(100 \%)$ \\
\hline \multicolumn{7}{|c|}{ Proficiencies Categorized by Quartiles } \\
\hline \multirow{2}{*}{ Top Quartile Average } & 0 & 50.9 & 16.4 & 18.9 & 47.7 & 133.9 \\
\hline & $(0 \%)$ & (38.9\%) & $(11.5 \%)$ & $(15.4 \%)$ & $(34.2 \%)$ & $(100 \%)$ \\
\hline \multirow{2}{*}{ Bottom Quartile Average } & 1.6 & 48.3 & 9.4 & 3.4 & 38.0 & 100.7 \\
\hline & $(0.9 \%)$ & $(52.4 \%)$ & $(7.4 \%)$ & $(4.1 \%)$ & $(35.2 \%)$ & $(100 \%)$ \\
\hline
\end{tabular}

Notes: ${ }^{a}$ Individual students are listed based on proficiency level, from the highest to the lowest, i.e., from H1 to H7 and then L7 to L1. ${ }^{\mathrm{b}}$ CL denotes clarification, ID identification, EX explanation, SG suggestion, and EN encouragement. 
Table 4. Words per comment

\begin{tabular}{|c|c|c|c|c|c|c|}
\hline \multirow{2}{*}{ Students ${ }^{\mathrm{a}}$} & \multicolumn{5}{|c|}{ Comment Types ${ }^{\text {b }}$} & \multirow{2}{*}{$\begin{array}{c}\text { Total } \\
\text { Comments }\end{array}$} \\
\hline & CL & ID & $\mathrm{EX}$ & SG & EN & \\
\hline H1 & 0 & 7.9 & 15.5 & 0 & 15.6 & 12.2 \\
\hline $\mathrm{H} 2$ & 0 & 7.3 & 14.0 & 15.0 & 9.5 & 9.3 \\
\hline H3 & 0 & 7.2 & 10.5 & 23.0 & 9.3 & 10.9 \\
\hline $\mathrm{H} 4$ & 0 & 7.3 & 0 & 0 & 8.0 & 7.6 \\
\hline H5 & 0 & 17.6 & 0 & 23.0 & 16.0 & 17.4 \\
\hline H6 & 0 & 3.0 & 8.0 & 15.0 & 14.0 & 7.6 \\
\hline H7 & 0 & 8.4 & 13.0 & 18.0 & 11.5 & 10.8 \\
\hline L1 & 0 & 4.7 & 0 & 0 & 0 & 4.7 \\
\hline L2 & 0 & 7.6 & 8.0 & 15.0 & 15.5 & 10.4 \\
\hline L3 & 11.0 & 10.5 & 21.0 & 0 & 19.0 & 13.7 \\
\hline L4 & 0 & 8.6 & 0 & 0 & 9.0 & 8.8 \\
\hline L5 & 0 & 13.2 & 0 & 0 & 13.0 & 13.1 \\
\hline L6 & 0 & 6.0 & 8.0 & 9.0 & 9.5 & 8.0 \\
\hline L7 & 0 & 13.0 & 0 & 0 & 14.8 & 13.9 \\
\hline \multicolumn{7}{|c|}{ Proficiencies Categorized by Extreme-Case Sampling } \\
\hline Top 3 Average & 0 & 7.5 & 13.3 & 12.7 & 11.5 & 10.8 \\
\hline Bottom 3 Average & 3.7 & 7.6 & 9.7 & 5.0 & 11.5 & 9.5 \\
\hline \multicolumn{7}{|c|}{ Proficiencies Categorized by Quartiles } \\
\hline Top Quartile Average & 0 & 8.4 & 8.7 & 13.4 & 12.0 & 10.8 \\
\hline Bottom Quartile Average & 1.6 & 9.1 & 5.3 & 3.4 & 11.5 & 10.3 \\
\hline
\end{tabular}

\section{Discussion}

Noteworthy findings have been observed in this study. First, the identification of problems was the major comment type for both the high- and low-performing writers. The number of comments provided by each group of writers in the category of identification accounted for approximately $50 \%$ to $70 \%$ of the total number of comments. As the primary comment type for both high- and low-proficiency learners, identifying problems was the easiest type of feedback to provide. In order to make peer review a more constructive and rewarding learning process for both the providers and receivers (Flower \& Hayes, 1981; Hyland, 2000) of peer review, learners of both high- and low-ability levels have to be trained adequately to move beyond the identification of problems. To achieve the objective, training sessions with clear teacher explanations and ample sample comments have to be 
provided. Since most students are unfamiliar with peer review, it is essential for teachers to demonstrate sample comments with elaborate explanations on the manner in which they may serve or fail to facilitate the subsequent revision of the writer. Based on the findings of the present study, both high- and low-proficiency learners require substantial guidance to move beyond problem identification. Therefore, it is imperative in the peer review training session to demonstrate constructive steps that peer reviewers can undertake after they have identified an area of concern.

In addition, as indicated through the analysis of word counts in each comment type, high-proficiency writers are more capable than their low-proficiency counterparts in elaborating their thoughts. Regardless of whether the five comment types were considered together or separately, higher word counts in the different comment types were observed for the high-performing writers. In particular, the high-performing writers provided more feedback in explaining the problems, making suggestions, and acknowledging the strength of the writing. This was observed regardless of whether the subgroups of different proficiencies were defined through extreme-case sampling or quartiles. The difference in the level of elaboration can be observed by the word counts in the different comment types in the extreme-case comparison pair (31.3 vs. 19.3, 20.3 vs. 5.0, and 52.0 vs. 33.3 words in explanation, suggestion, and encouragement, respectively) and the top and bottom quartile comparison pair (16.4 vs. 9.4, 18.9 vs. 3.4, and 47.7 vs. 38.0 words, respectively). This is consistent with the general belief that superior writers are more proficient elaborating their thoughts (Leki, Cumming, \& Silva, 2008; Zainuddin \& Moore, 2003).

The results of word counts per comment provided further evidence that high-performing writers elaborated more when they made suggestions for revision (12.7 vs. 5.0 words per suggestion comment in the extreme-case comparison pair and 13.4 vs. 3.4 words in the quartile comparison pair). Although the variation in quantity and quality of comments can be attributed to writing ability, reading ability is also a possible factor (Delaney, 2008). As pointed out by Kennedy (1985), reading-to-write performance can be affected by the reading ability of learners. The elaboration of the content of writing may be restricted when limited by reading competence.

Consequently, in order to maximize the positive effects of peer review and minimize possible frustration when receiving peer comments, two or more peer review training cycles in which every learner comments on an identical sample of writing are strongly recommended before proceeding to the phase in which writers provide peer comments on each other's writing. The logic behind this recommendation is to create a platform for scaffolding, in which peer modeling, interactive whole-class discussion, effective comparison of comments among peers, and more in-depth teacher demonstrations and explanations can be conducted. This is especially essential for lower-proficiency learners due to their competence at both the sentence and discourse levels.

The idea to offer sufficient peer review training through more than one training cycle is in line with the findings of prior research. For example, when discussing potential pitfalls of peer-assisted learning, Maheady (2009) indicated that quality control of peer assistance is a major concern in incorporating peer learning. Maheady strongly recommended that students must be systematically trained in their collaborative roles before peer learning is implemented. Likewise, Min (2003) analyzed 352 peer comments on 24 first drafts and discovered that $62 \%$ of the comments were not incorporated into the subsequent revisions. Min, therefore, recommended the use of clearly-structured review steps and a teaching-learning cycle that circulates examples of efficient peer comments and analyzed the manner in which to make comments helpful. Berg (1999) and Min (2006) also stressed the importance of step-by-step training.

\section{Conclusion and Pedagogical Implications}

The present study compared the comments of high- and low-proficiency L2 learners in five comment types: asking for clarification, identifying problems, explaining the problems, making suggestions for revisions, as well as acknowledging the strength of writing and encouraging the writer. High- and low-proficiency learners were differentiated using two approaches. One approach was sorting the students into a top quartile, a bottom quartile, and a middle $50 \%$, and then taking the first two groups as the subjects in the present study. The other approach was using extreme-case sampling for a clear-cut comparison.

The primary comment type used by both high- and low-proficiency writers was identification of problems. To assist L2 learners to move beyond problem identification and to make peer feedback a rewarding experience, this study presents three implications to writing instruction incorporating peer review training. First of all, L2 learners, regardless of their English proficiency levels, should be provided with adequate peer review training and be explicitly encouraged to move beyond identification of problems. Furthermore, peer review training sessions should contain ample sample comments, clear teacher explanations, peer modeling, and active whole-class discussion. In addition, mock peer reviews on sample writing should be conducted before learners 
actually critique each other's writing.

\section{Limitation and Suggestions for Further Research}

As in other studies, the present study has limitations. First, the results are generalizable to L2 learners of similar English proficiency levels, that is, CEFR A2 (elementary) and B1 (pre-intermediate) levels as shown in Table 1. Furthermore, learners of different English levels exhibited differing performance in all comment types except asking for clarification and identifying problems. Better writers provided more feedback in the areas of explanation of problems, suggestions for revisions, and encouragement to peers. Nevertheless, it is worth noticing that the definition of "more" feedback in the present study was determined quantitatively by word counts. Therefore, the definition may be limited in nature and unable to get the full picture regarding the quality of comments. It is thus recommended that future research with qualitative analysis be conducted in order to discover whether the feedback provided by the higher-performing writers is indeed better in content. Two possible areas of analysis are the types of problems that reviewers identify and the types of suggestions that they provide.

Additionally, it is suggested that interviews with learners, particularly those with less proficient writing skills, be conducted to learn their reviewing process and whether their own revision strategies may have led them to focus on certain comment types. Writing strategy questionnaires can also be utilized to facilitate the understanding. Moreover, this study examined variations in peer review comments in order to provide insights as how to construct helpful peer review training. It is recommended that future study be conducted to scrutinize the effects of the interplay of peer review instruction and language proficiency on peer review performance.

To sum up, the study offers the following suggestions for future research. Firstly, qualitative analysis on peer comments can be conducted to understand how high- and low-performing writers vary in the nature of problems that they identify and the suggestions that they provide. Secondly, interviews can be conducted to explore possible relationships among the reviewing processes of the learners, the revision strategies that they usually implement, and the comment types that they use more (or less) frequently. Thirdly, writing strategy questionnaires can be administered to assist the above exploration. Finally, training in peer review should be provided in future studies and the effects of the training on peer review behaviors and effectiveness be examined.

\section{References}

Bargiela-Chiappini, F., \& Nickerson, G. (Eds.). (1999). Writing business genres, media and discourse. London, United Kingdom: Longman.

Berg, E. C. (1999). The effects of trained peer response on ESL students' revision types and writing quality. Journal of Second Language Writing, 8, 215-241. http://dx.doi.org/10.1016/S1060-3743(99)80115-5

Cohen, A., \& Cavalcanti, M. (1990). Feedback on compositions: Teacher and student verbal reports. In B. Kroll (Ed.), Second language writing: Research insights for the classroom (pp. 155-178). Cambridge, United Kingdom: Cambridge University Press.

Connor, U., \& Krammer, M. (1995). Writing from sources: Case studies of graduate students in business management. In D. Belcher \& G. Braine (Eds.), Academic writing in a second language: Essays on research and pedagogy (pp. 155-182). Norwood, NJ: Ablex.

Delaney, Y. A. (2008). Investing the reading-to-write construct. Journal of English for Academic Purposes, 7 , 140-150. http://dx.doi.org/10.1016/j.jeap.2008.04.001

Dewey, J. (1963). Experience and education. New York: Collier Books.

Flower, L., \& Hayes, J. (1980). The cognition of discovery: Defining a rhetorical problem. College Composition and Communication, 31, 21-32. http://dx.doi.org/10.2307/356630

Flower, L. \& Hayes, J. (1981). A cognitive process theory of writing. College Composition and Communication, 32, 365-387. http://dx.doi.org/10.2307/356600

Hyland, F. (2000). ESL writers and feedback: Giving more autonomy to learners. Language Teaching Research, 4, 33-54.

Hyland, K. (2003). Second language writing. London, United Kingdom: Cambridge University Press. http://dx.doi.org/10.1017/CBO9780511667251

Kennedy, M. (1985). The composing process of college students writing from sources. Written Communication, 2, 434-456. http://dx.doi.org/10.1177/0741088385002004006 
Leki, I., Cumming, A., \& Silva, T. (2008). A synthesis of research on second language writing in English. New York: Taylor and Francis.

Maheady, L. (2009). Advantages and disadvantages of peer-assisted learning strategies. In K. Topping, \& S. Ehly (Eds.), Peer-assisted learning (pp. 46-68). Mahwah, NJ: Taylor and Francis.

McMillan, J. H., \& Schumacher, S. (1997). Research in education: A Conceptual introduction (4th ed.). New York: Longman.

Mendonca, C. O., \& Johnson, K. E. (1994). Peer review negotiations: Revision activities in ESL writing instruction. TESOL Quarterly, 28(4), 745-769. http://dx.doi.org/10.2307/3587558

Min, H. T. (2003). Why peer comments fail. English Teaching and Learning, 27(3), 85-103.

Min, H. T. (2005). Training students to become successful peer reviewers. System, 33, 293-308. http://dx.doi.org/10.1016/j.system.2004.11.003

Min, H. T. (2006). The effects of trained peer review on EFL students' revision types and writing quality. Journal of Second Language Writing, 15, 118-141. http://dx.doi.org/10.1016/j.jslw.2006.01.003

Min, H. T. (2009). Peer review training and teacher feedback. In Proceedings of the 26th international conference on English teaching and learning in the R.O.C. (pp. 625-629). Taipei, Taiwan: Crane.

Pianko, S. (1979). A description of composing processes of college freshmen writers. Research in the Teaching of English, 13, 5-22.

Plakans, L. (2008). Comparing composing processes in writing-only and reading-to-write test tasks. Assessing Writing, 13, 111-129. http://dx.doi.org/10.1016/j.asw.2008.07.001

Porte, G. (1996). When writing fails: How academic context and past learning experiences shape revision. System, 24, 107-116. http://dx.doi.org/10.1016/0346-251X(95)00056-P

Porte, G. K. (1997). The etiology of poor second language writing: The influence of perceived teacher preferences on second language revision strategies. Journal of Second Language Writing, 6, 61-78. http://dx.doi.org/10.1016/S1060-3743(97)90006-0

Roca de Larios, J., Manchon, R., Murphy, L., \& Marin, J. (2008). The foreign language writers' strategic behaviour in the allocation of time to writing processes. Journal of Second Language Writing, 17, 30-47. http://dx.doi.org/10.1016/j.jslw.2007.08.005

Roca de Larios, J., Murphy, L., \& Marin, J. (2002). A critical examinatin of L2 writing process research. In S. Ransdell, \& M. L. Barbier (Eds.), New directions for research in L2 writing (pp. 11-47). Dordrecht, Netherlands: Kluwer. http://dx.doi.org/10.1007/978-94-010-0363-6_2

Stanley, J. (1992). Coaching student writers to be effective peer evaluators. Journal of Second Language Writing, 1, 217-233. http://dx.doi.org/10.1016/1060-3743(92)90004-9

Stoddard, B., \& MacAuthur, C. (1993). A peer editor strategy: Guiding learning disabled students in response and revision. Research in the Teaching of English, 27(1), 76-103.

Tang, G. M., \& Tithecott, J. (1999). Peer response in ESL writing. TESL Canada Journal, 16(2), 20-38.

Villamil, O., \& De Guerrero, M. (1996). Peer revision in the second language classroom: Social cognitive activities, mediating strategies and aspects of social behavior. Journal of Second Language Writing, 3(1), 51-57. http://dx.doi.org/10.1016/S1060-3743(96)90015-6

Vygotsky, L. S. (1962). Thought and language. Cambridge, MA: MIT Press.

Vygotsky, L. S. (1978). Mind in society: The development of higher psychological processes. Cambridge, MA: Harvard University Press.

Zainuddin, H., \& Moore, R. A. (2003). Audience awareness in L1 and L2 composing of bilingual writers. TESL-EJ, 7(1), 1-18.

Zamel, V. (1982). Writing: The process of discovering meaning. TESOL Quarterly, 16, 195-210. http://dx.doi.org/10.2307/3586792

Zamel, V. (1983). The composing processes of advanced ESL students: Six case studies. TESOL Quarterly, 17, 165-186. http://dx.doi.org/10.2307/3586647 